\title{
Avanços no design da experiência do usuário de um tradutor entre línguas de sinais
}

\author{
Josué I. Cruz-Cortez ${ }^{1}$, J. Alfredo Sánchez ${ }^{1}$, Soraia Silva Prietch ${ }^{2}$ \\ ${ }^{1}$ Laboratório Nacional de Informática Avançada (LANIA) \\ Rébsamen 80, Xalapa, Veracruz 91090, México \\ ${ }^{2}$ Curso de Sistemas de Informação - Universidade Federal de Rondonópolis \\ Av. dos Estudantes, 5055 - 78.736-901 - Rondonópolis - MT - Brasil \\ \{jcruz.mca20, alfredo.sanchez\}@lania.edu.mx, soraia@ufr.edu.br
}

\begin{abstract}
This paper reports on advances in user experience design for a translator between sign languages. Specifically, we aim to support the communication between users of LSM (Mexican Sign Language) and Libras (Brazilian Sign Language). We report on preliminary results of a systematic literature review of related work and observations derived during the application of the early stages of the Lean UX methodology.

Resumo. Este artigo apresenta avanços no design da experiência do usuário para um tradutor entre línguas de sinais. Especificamente, pretendemos apoiar a comunicação entre usuários da LSM (Lengua de Señas Mexicana) e da Libras (Lingua Brasileira de Sinais). São apresentados resultados preliminares de uma revisão sistemática da literatura de trabalhos correlatos e observações derivadas durante a aplicação dos estágios iniciais da metodologia Lean UX.
\end{abstract}

\section{Introdução}

Dentro das comunidades surdas, o uso de línguas de sinais (LS), assim como o de línguas orais ou escritas é muito variável, dependendo de diversos fatores no desenvolvimento do indivíduo [Cruz-Aldrete, 2009]. Existem diversas LS oficiais, com variações significativas segundo o país e ainda a nível regional dentro de países. Dadas as condições de desvantagem e exclusão das comunidades surdas, é importante compartilhar suas experiências e seus interesses para que, progressivamente, possamos nos tornar uma sociedade mais inclusiva. Infelizmente, a comunicação direta entre comunidades surdas que usam LS distintas é um desafio que ainda não se existem muitos trabalhos na área de Tecnologia Assistiva.

Existem avanços nas tecnologias que auxiliam na tradução de uma língua oral ou escrita para uma língua de sinais [Pichardo et al., 2016], assim como em aplicações que buscam construir dicionários multilíngues que relacionam sinais de uma língua com os de outras [Spread the sign, 2018]. Mesmo que os resultados destes projetos possam ser úteis na comunicação entre pessoas surdas que usam LS distintas, seu desenvolvimento ainda é incipiente, além do fato de que não privilegiam usuários surdos. Isto é, suas interfaces levam a entender que seus usuários podem utilizar, ao menos, uma língua escrita ou oral.

Cada grupo da comunidade surda tem necessidades e motivações particulares que devem ser consideradas no design de tecnologias. Sendo assim, é possível projetar uma 
ferramenta, que seja útil para a tradução entre LS, pensando sobre a experiência do usuário e incluindo as comunidades surdas envolvidas.

Este artigo relata sobre os avanços de um projeto de design da experiência do usuário com um tradutor entre línguas de sinais, especificamente entre a Língua de Sinais Mexicana (LSM, Lengua de Señas Mexicana) e a Língua Brasileira de Sinais (Libras). São descritos os resultados iniciais de uma revisão sistemática realizada para situar o projeto no contexto de outros avanços na área, assim como as observações iniciais de reuniões com usuários realizadas como parte da aplicação da metodologia Lean UX [Gothelf e Seiden, 2013].

\section{Trabalhos correlatos}

Para fundamentar e contextualizar o projeto, uma revisão sistemática de literatura (RSL) foi iniciada. Por motivos de espaço, apresentamos apenas um resumo dos resultados da busca e filtro de documentos. Foram selecionados 25 artigos, organizados em 4 categorias: projeto de tecnologias para pessoas surdas (8), métodos de tradução (12), aspectos chave de tradução (4) tendo uma língua de sinais como entrada ou saída, e tradutores entre línguas de sinais (1). Como pode-se observar, foram identificados poucos trabalhos em aspectos chave da tradução para LS, enquanto que a investigação sobre a tradução entre LS ainda é incipiente.

Entre os artigos selecionados sobre o projeto de tecnologias para pessoas surdas cabe destacar que Erard (2017) enfatiza que os desenvolvedores não são os usuários, o que reforça que é fundamental incluir a comunidade surda em todas as etapas do desenvolvimento de produtos ou serviços. Na categoria de métodos de tradução de (ou para) LS, os trabalhos se enfocam em ferramentas de tradução a partir de um idioma escrito ou oral. Um exemplo é o tradutor de Espanhol para Língua de Sinais Espanhola (LSE, Lengua de Signos Española) descrito por San-Segundo et al. (2010). Aspectos chave da tradução de (ou para) LS incluem trabalhos que descrevem propostas ou considerações as quais se deve levar em conta ao desenvolver este tipo de tecnologia, uma vez que, como mencionam Bragg et al. (2019), a tradução, o reconhecimento e a geração de sinais requerem conhecimentos de várias áreas. Finalmente, com base em nossos critérios de seleção, se incluiu unicamente um trabalho de um tradutor entre as LS coreana e japonesa [Liu, 2010].

\section{Design da experiência do usuário de um tradutor entre LSM e Libras}

O objetivo principal do projeto que aqui se apresenta é projetar a experiência do usuário para um tradutor entre LSM e Libras. Para isso, estamos usando a Lean UX, uma metodologia para desenvolver produtos e serviços em conjunto com os usuários. De maneira abreviada, em Lean UX, os desenvolvedores e usuários iteram de forma colaborativa em quatro etapas: propor e validar suposições, construir um produto mínimo viável, realizar experimentos com o produto proposto, e analisar o conhecimento adquirido. Atualmente, a primeira iteração está em processo, com avanços em duas etapas: (1) análise de conhecimento adquirido, mediante a RSL, participação em cursos de LS e imersão dos investigadores em comunidades surdas do México e do Brasil, e (2) proposta e validação de suposições, mediante um encontro planejado entre desenvolvedores e usuários de ambas comunidades.

A Figura 1 ilustra o cenário da reunião virtual planejada entre sete participantes durante a atividade de investigação de validação de suposições. Como pode-se observar, do México, participaram uma pessoa surda, usuária de LSM, e um intérprete de LSM, assim 
como dois investigadores ouvintes, usuários de língua espanhola falada e escrita, que atuaram como facilitadores. Do Brasil, participaram uma pessoa surda, usuária de Libras, e uma intérprete de Libras, assim como uma investigadora ouvinte, usuária de língua portuguesa falada e escrita, quem também atuou como facilitadora. Mesmo que o objetivo primário do encontro tenha sido revisar as suposições dos investigadores a respeito da necessidade e das características de um tradutor entre LS, objetivos secundários incluíram a oportunidade para gerar maior empatia entre os participantes, assim como observar em primeira mão os desafios que implica a comunicação entre pessoas que usam LS distintas.

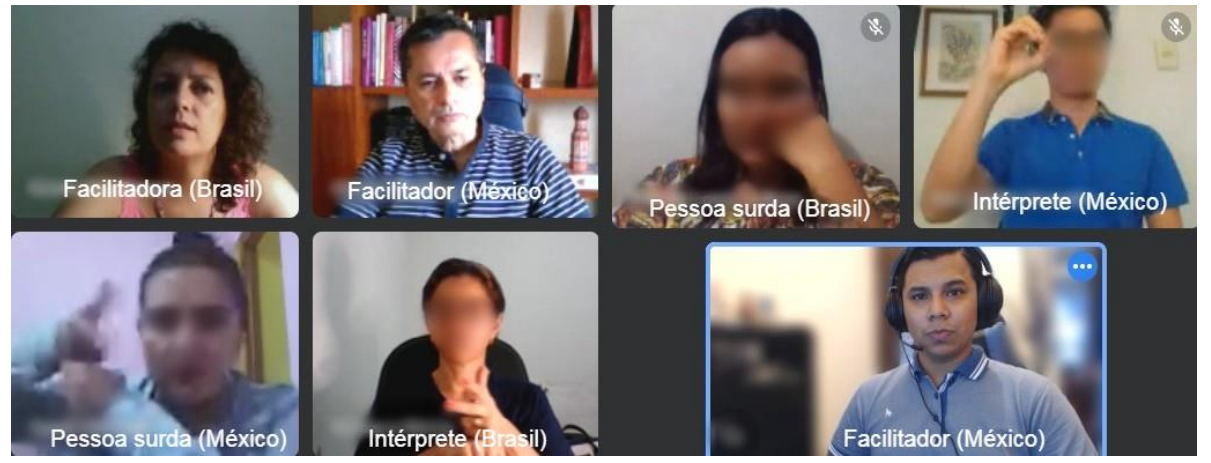

Figura 1. Encontro para validar suposições sobre um tradutor entre LS.

Com respeito à proposta de um tradutor entre LS, os participantes surdos e os intérpretes se mostraram céticos inicialmente, uma vez que associaram o conceito de tradutor a tecnologias existentes que envolvem o uso de línguas escritas ou orais. Ao esclarecer que se trata de uma proposta que prioriza usuários surdos, e que lhes permitirá se comunicar com membros de comunidades surdas que usam outras LS, se mostraram mais receptivos e expressaram interesse em aplicações adicionais para conhecer e aprender outras LS, assim como seus potenciais usos em viagens e em videochamadas.

A própria reunião serviu para motivar a necessidade e a utilidade potencial do tradutor proposto. Durante esta, se realizou uma dinâmica de comunicação entre as duas pessoas surdas sem o auxílio dos intérpretes. Ainda que a dinâmica tenha consistido em um exercício de comunicação básica, as participantes puderam superar algumas das diferenças entre suas LS. Com isso, o grupo concluiu que seria útil contar com ferramentas de tradução para tornar possível uma comunicação mais fluída e inteligível em um cenário mais geral.

\section{Trabalho em processo e futuro}

Embora o design de nosso tradutor entre LS tenha recém iniciado, as evidências preliminares são encorajadoras sobre seu potencial. Por outro lado, facilitar a comunicação entre LS distintas (LSM e Libras) imersas em línguas orais e escritas também distintas (espanhol e português) têm implicações sobre o design da experiência de usuário que somente agora estamos conhecendo e explorando. Atualmente, a RSL está sendo ampliada e o vídeo da primeira atividade de investigação com os participantes está sendo analisado em detalhe. Com base nisto, avançaremos para as etapas seguintes de Lean UX: construir produtos mínimos viáveis, experimentação, e aproveitamento do conhecimento adquirido. Finalmente, o design da experiência do usuário deve ser a base para a construção de um tradutor entre LS que as comunidades surdas se apropriem para se comunicar e se fortalecer mutuamente. 


\section{Referências}

Bragg, D., Koller, O., Bellard, M., Berke, L., Boudreault, P., Braffort, A. \& Ringel Morris, M. (2019). Sign language recognition, generation, and translation: An interdisciplinary perspective. In The 21st international ACM SIGACCESS conference on computers and accessibility, October, (pp. 16-31).

Cruz-Aldrete, M. C. (2009). Gramática de la lengua de señas mexicana. Estudios de lingüística del español, (28), 1.

Erard, M. (2017). Why Sign-Language Gloves Don't Help Deaf People. The Atlantic 9 (2017).

Gothelf, J., \& Seiden, J. (2013). Lean UX: Applying lean principles to improve user experience. [S1]: O’Reilly Media.

Liu, Z., Zhang, X., \& Kato, J. (2010, August). Research on Chinese-Japanese Sign Language Translation System. In 2010 Fifth International Conference on Frontier of Computer Science and Technology (pp. 640-645). IEEE.

Pichardo-Lagunas, O., Partida-Terrón, L., Martínez-Seis, B., Alvear-Gallegos, A., \& Serrano-Olea, R. (2016). Sistema de traducción directa de español a LSM con reglas marcadas. Res. Comput. Sci., 115, 29-41.

San-Segundo, R., Pardo, J. M., Ferreiros, J., Sama, V., Barra-Chicote, R., Lucas, J. M. \& García, A. (2010). Spoken Spanish generation from sign language. Interacting with Computers, 22(2), 123-139.

Spread the sign. (2018). Disponível em: https://www.spreadthesign.com/. Acesso em 11 out. 2021. 